\title{
SOROPREVALÊNCIA DE INFECCÕES E RISCOS OCUPACIONAIS RELACIONADOS AOS CATADORES DE RESÍDUOS SÓLIDOS DO EXTREMO NORTE DO BRASIL
}

\section{SEROPREVALENCE OF INFECTIONS AND OCCUPATIONAL RISKS RELATED TO COLLECTORS OF SOLID WASTE FROM THE EXTREM NORTH OF BRAZIL}

\author{
Raphael Barros Rocha \\ Acadêmico de Medicina - Universidade Federal de Roraima \\ Centro de Ciências da Saúde/Universidade Federal de Roraima \\ raphaelbarrosrocha@gmail.com \\ João Victor Satrapa Silva \\ Acadêmico de Medicina - Universidade Federal de Roraima \\ Centro de Ciências da Saúde/Universidade Federal de Roraima \\ jvsatrapa@gmail.com \\ Áurea Sérgia da Silva Macêdo \\ Acadêmica de Medicina - Universidade Federal de Roraima \\ Centro de Ciências da Saúde/Universidade Federal de Roraima \\ aureasergia@gmail.com \\ Jamilla Karla Corrêa Reis \\ Mestranda em Ciências da Saúde - Universidade Federal de Roraima \\ Programa de Pós-graduação em Ciências da Saúde/Universidade Federal de Roraima \\ jamillacorrea20@gmail.com \\ Wagner do Carmo Costa \\ Mestre em Ciências da Saúde - Universidade Cruzeiro do Sul \\ Assessor/Assembleia Legislativa de Roraima \\ wagner@vitalizar.com \\ Ana lara Costa Ferreira \\ Doutora em Ciências da Saúde - Faculdade de Medicina de São José do Rio Preto \\ Docente do Programa de Pós-graduação em Saúde e Biodiversidade/Universidade Federal de Roraima \\ ana.ferreira@ufrr.br \\ Doutora em Genética, Conservação e Biologia Evolutiva - Instituto Nacional de Pesquisas na Amazônia \\ Docente do Programa de Pós-graduação em Saúde e Biodiversidade/ Universidade Federal de Roraima \\ leila.ribeiro@ufrr.br \\ Fabiana Nakashima \\ Doutora em Ciências da Saúde - Faculdade de Medicina de São José do Rio Preto \\ Docente do Programa de Pós-graduação em Saúde e Biodiversidade/ Universidade Federal de Roraima \\ fabiana.nakahima@ufrr.br \\ Bruna Kempfer Bassoli \\ Doutora em Ciências - Universidade de São Paulo \\ Docente do Programa de Pós-graduação em Ciências da Saúde/ Universidade Federal de Roraima \\ bruna.bassoli@ufrr.br \\ Bianca Jorge Sequeira \\ Doutora em Biologia dos Agentes Infecciosos e Parasitários - Universidade Federal do Pará \\ Docente do Programa de Pós-graduação em Ciências da Saúde/ Universidade Federal de Roraima \\ bianca.costa@ufrr.br
}

\section{RESUMO}

Introdução: As atividades ocupacionais relacionadas aos catadores de resíduos sólidos, estão associadas à diversos riscos de cunho biológico, físico, químico, ergonômico, além dos acidentes de trabalho. Objetivo: descrever a prevalência da infecção por agentes virais (Vírus HIV e Vírus da Hepatite B e C) e bacterianos (Treponema pallidum) e avaliar o nível

Recebido em: 18/02/2021

Aceito para publicação em: 13/06/2021. 
Soroprevalência de infecções e riscos ocupacionais relacionados aos catadores de resíduos sólidos do extremo norte do Brasil
Raphael Barros Rocha

João Victor Satrapa Silva

Áurea Sérgia da Silva Macêdo

Jamilla Karla Corrêa Reis Wagner do Carmo Costa

Ana lara Costa Ferreira Leila Braga Ribeiro

Fabiana Nakashima

Bruna Kempfer Bassoli

Bianca Jorge Sequeira

de exposição à riscos ocupacionais dos indivíduos vinculados à cooperativas de catadores de lixo de Boa Vista-Roraima. Métodos: estudo transversal, prospectivo, descritivo, qualitativo e quantitativo, envolvendo 75 indivíduos, de 18 a 70 anos, que atuam como catadores de resíduos sólidos em duas Cooperativas de Reciclagem, na cidade de Boa Vista, Roraima. Foi realizada a investigação dos dados sociodemográficos e ocupacionais por meio da aplicação de um questionário e realizados testes rápidos para detecção de HIV 1 e 2, sífilis e hepatites B e C. Resultados: a prevalência de infecções foi de $4 \%$ na amostra analisada, uma vez que três participantes apresentaram diagnóstico positivo para sífilis. Houve associação estatisticamente significativa entre trabalhar há mais tempo como catador e ser mulher e trabalhar há mais tempo como catador e ter baixa escolaridade. Os principais riscos ocupacionais observados foram postura inadequada, levantamento de cargas pesadas, trabalho em pisos irregulares e manipulação de equipamentos possivelmente lesivos. Conclusão: faz-se necessária a criação de políticas públicas que atendam às necessidades destes trabalhadores e a implementação de um processo de educação continuada que aborde os riscos ocupacionais e a importância da utilização correta dos EPIs.

Palavras-chave: Catador de resíduos sólidos. Infecção. Risco ocupacional.

\begin{abstract}
Introduction: Occupational activities related to solid waste collectors are associated with several biological, physical, chemical and ergonomic risks in addition to occupational acidentes. Objective: to describe the prevalence of infection by viral (HIV virus and Hepatitis $\mathrm{B}$ and $\mathrm{C}$ virus) and bacterial (Treponema pallidum) agents and to evaluate the level of exposure to occupational risks of individuals linked to the cooperatives of garbage collectors in Boa Vista-Roraima. Methods: cross-sectional, prospective, descriptive, qualitative and quantitative study, involving 75 individuals, from 18 to 70 years old, who act as solid waste collectors in the Global Solid Waste Recycling Cooperatives and Terra Viva, in the city of Boa Vista, Roraima. The investigation of sociodemographic and occupational data was carried out through the application of a questionnaire and rapid tests were performed for the detection of HIV 1 and 2, syphilis and hepatitis B and C. Results: the prevalence of infections was $4 \%$ in the sample analyzed, a since three participants had a positive diagnosis for syphilis. There was a statistically significant association between working longer as a collector and being a woman and working longer as a collector and having low education. The main occupational risks observed were inadequate posture, lifting heavy loads, working on uneven floors and handling possibly harmful equipment. Conclusion: it is necessary to create public policies that meet the needs of these workers and to implement a continuing education process that addresses occupational risks and the importance of the correct use of IPE.
\end{abstract}

Keywords: Solid waste collector. Infeccion. Occupational risk.

\title{
INTRODUÇÃO
}

A saúde ocupacional está relacionada à promoção de condições que garantam qualidade de vida no trabalho, protegendo a saúde dos trabalhadores, promovendo o bem-estar físico, mental e social, prevenindo e controlando os acidentes de trabalho e as doenças através da redução das condições de risco, cabendo ao empregador definir e informar acerca dos riscos potenciais do trabalho e garantir locais de trabalho seguros e saudáveis (MONIZ, 2016).

Conforme o Censo de 2010, existem 387.910 catadores no Brasil, entretanto, o Movimento Nacional de Catadores de Materiais Recicláveis (MNCR) pondera que o Censo não chega aos lixões nem aos catadores em situação de rua, assim, o número chegaria a 1 milhão de catadores (SANTOS, 2018). Aos catadores são atribuídas, de forma geral, as atividades de catar, separar, transportar, armazenar e vender os resíduos (SILVA; GOES; ALVAREZ, 2013)

$\begin{array}{lllllll}\text { Hygeia } & \text { Uberlândia - MG } & \text { v. 18 } & 2022 & \text { p. 29-43 } & \text { Página } & 30\end{array}$


Soroprevalência de infecções e riscos ocupacionais relacionados aos catadores de resíduos sólidos do extremo norte do Brasil
Raphael Barros Rocha

João Victor Satrapa Silva Áurea Sérgia da Silva Macêdo Jamilla Karla Corrêa Reis Wagner do Carmo Costa

Ana lara Costa Ferreira Leila Braga Ribeiro

Fabiana Nakashima

Bruna Kempfer Bassoli

Bianca Jorge Sequeira

As atividades ocupacionais relacionadas aos catadores estão associadas à diversos riscos de cunho biológico, físico, químico, ergonômico, além dos acidentes de trabalho (GALON; MARZIALE, 2016). Muitos acidentes que acabam ocasionando lesões ou ferimentos, muitas vezes são provocados devido a presença de materiais perfurocortantes, como vidros, lâminas e agulhas, e, ainda, pelo contato com matérias em decomposição, como os resíduos orgânicos, que podem levar a contaminações graves, uma vez que nesses espaços há a presença de espécies fúngicas (SOUZA, 2015). Dessa maneira, esses indivíduos, ficam sujeitos a exposição diária a riscos químicos e biológicos, além de atuarem em um local de trabalho de alta insalubridade (LAZZARI; REIS, 2011).

Os resíduos sólidos, ou seja, o lixo, não devem ser considerados como meio principal de contaminação, porém o seu descarte inadequado pode gerar a proliferação de patógenos disseminadores de diversos agravos e patologias, os quais podem ser transmitidos aos trabalhadores que os manipulam. Vale ressaltar que a cidade de Boa Vista, capital do estado de Roraima, não possui coleta seletiva de lixo, fato que potencializa ainda mais a possibilidade de os catadores manipularem resíduos contaminados, algumas vezes até com fluidos orgânicos.

Em razão de os catadores atuarem em um ambiente com alta insalubridade, é de suma importância o acompanhamento das suas condições de saúde, como a correta utilização dos equipamentos de proteção individual (EPIs). Desta forma, considerando o impacto do risco ocupacional biológico e a exposição no ambiente de trabalho, este estudo buscou descrever a soroprevalência da infecção por agentes virais (Vírus HIV e Vírus da Hepatite B e C) e bacterianos (Treponema pallidum) e avaliar o nível de exposição à riscos externos e as condições de trabalho dos indivíduos vinculados às cooperativas de catadores de lixo de Boa Vista.

\section{MÉTODOS}

Trata-se de um estudo transversal, prospectivo, descritivo, com caráter qualitativo e quantitativo, envolvendo 75 indivíduos, na faixa etária de 18 a 70 anos, independente do gênero, que exercem a atividade de catadores de resíduos sólidos nas Cooperativas de Reciclagem de Resíduos Sólidos Global e Terra Viva, localizadas na cidade de Boa Vista, Roraima.

Após a assinatura do TCLE foi realizada a investigação dos dados sociodemográficos por meio da aplicação de um questionário estruturado e o levantamento das informações relacionadas a atividade laboral, por meio do Questionário sobre condições de trabalho, emprego e saúde na América Latina e Caribe adaptado.

Após a coleta dos dados, foram realizados os testes rápidos para detectar infecções transmissíveis (HIV 1 e 2, sífilis e hepatites B e C). Em caso de testes reagentes, o participante foi encaminhado à Unidade Básica de Saúde (UBS) mais próxima para realização de exames complementares, comprovação do resultado e início do tratamento.

O diagnóstico da presença dos vírus HIV 1 e 2 foi realizado através do teste rápido (MedTeste Biotest). Trata-se de um imunoensaio cromatogáfico para a detecção qualitativa dos anticorpos do HIV tipo 1 e tipo 2. Para avaliar a prevalência da sífilis, foi realizado um teste rápido imunocromatográfico para a detecção de anticorpos anti-treponema (Imuno-rápido Sífilis; Wama Diagnóstica) para determinação qualitativa de anticorpos (IgG e $\operatorname{lgM}$ ) anti-Treponema pallidum. Para a detecção da Hepatite $B$, foi utilizado o teste imunocromatográfico rápido para determinação qualitativa de antígeno de superfície do vírus da Hepatite B (HBsAg/subtipos ad e ay) em amostras de soro humano, plasma ou sangue total (Bioclin HBsAg 145) e para o diagnóstico da Hepatite C, utilizou-se o teste rápido imunocromatográfico - teste rápido HCV (Alere HCV). Vale ressaltar que todos os testes foram realizados seguindo a metodologia proposta pelos fabricantes.

Os dados coletados foram tabulados no software Microsoft Excel versão 10. Foram realizadas análises descritivas e inferenciais. Utilizou-se o programa Epi Info (CDC) versão 7.2.3.1 para a análise univariada, feita por meio do teste do $x^{2}$, considerando o nível de significância de $5 \%(p<$ $0,05)$. Este estudo foi aprovado pelo Comitê de Ética em Pesquisa da Universidade Federal de Roraima (Parecer: 3.598.802). 
Soroprevalência de infecções e riscos ocupacionais relacionados aos catadores de resíduos sólidos do extremo norte do Brasil
Raphael Barros Rocha João Victor Satrapa Silva Áurea Sérgia da Silva Macêdo Jamilla Karla Corrêa Reis Wagner do Carmo Costa Ana lara Costa Ferreira Leila Braga Ribeiro Fabiana Nakashima Bruna Kempfer Bassoli Bianca Jorge Sequeira

\section{RESULTADOS}

Ao avaliar os dados sociodemográficos dos 75 participantes (Tabela 1), observou-se que a maioria deles pertence a faixa etária de 40 a 49 anos (22 participantes/29,3\%), seguidos daqueles que têm entre 29 e 39 anos (20 participantes/26,7\%). A média da idade foi de 38,3 anos e seu desvio padrão de 12,45. A maior parte dos participantes são mulheres (51) correspondendo a $68,0 \%$ do universo amostral.

Quando questionados se tinham filhos, 59 participantes (78,7\%) afirmaram que sim, apresentando uma média de 4,54 filhos com desvio padrão de 2,38. Já com relação a raça/cor, evidenciou-se maior prevalência dos que se autodeclararam pardos (57 participantes $/ 76,0 \%$ ), seguidos dos negros (09 participantes $/ 12,0 \%)$.

Quanto a escolaridade, percebe-se que apesar da grande maioria dos participantes ter o ensino fundamental incompleto (46 participantes/61,3\%), 13 (17,3\%) haviam concluído o ensino médio e 02 $(2,7 \%)$ possuíam o ensino superior completo. No tocante a renda familiar mensal, a renda de até 1 salário mínimo foi a mais prevalente (74 participantes $/ 98,7 \%$ ) e apenas um participante do estudo relatou receber mais do que um salário $(1,3 \%)$, mais especificamente entre 1 e 3 salários mínimos.

A maior parte dos participantes $(86,7 \%)$ declarou possuir uma religião, sendo mais frequentes os evangélicos (48 participantes/73,8\%), seguidos dos católicos (16 participantes/;24,6\%). Um único participante que declarou ter religião, não respondeu a qual pertencia.

Quanto ao tempo de trabalho como catador de recicláveis, 72,0\% possui essa ocupação há mais de 3 anos. É importante citar que 24 pessoas afirmaram exercer essa atividade laboral há mais de 10 anos. A média de tempo de trabalho dos participantes como catadores foi de 7,56 anos com desvio padrão de 6,69.

Tabela 1 - Perfil sociodemográfico dos catadores de resíduos sólidos vinculados às cooperativas de reciclagem Global e Terra Viva, Boa Vista, Roraima.

\begin{tabular}{|c|c|c|}
\hline Variável & $\begin{array}{l}\text { Frequência } \\
\text { Absoluta (n) }\end{array}$ & $\begin{array}{l}\text { Frequência } \\
\text { Relativa (\%) }\end{array}$ \\
\hline $\begin{array}{l}\text { Faixa etária } \\
18-28 \text { anos } \\
29-39 \text { anos } \\
40-49 \text { anos } \\
50-59 \text { anos } \\
\text { Acima de } 60 \text { anos }\end{array}$ & $\begin{array}{l}19 \\
20 \\
22 \\
11 \\
03\end{array}$ & $\begin{array}{l}25,3 \\
26,7 \\
29,3 \\
14,7 \\
4,0\end{array}$ \\
\hline $\begin{array}{l}\text { Sexo } \\
\text { Masculino } \\
\text { Feminino }\end{array}$ & $\begin{array}{l}24 \\
51\end{array}$ & $\begin{array}{l}32,0 \\
68,0\end{array}$ \\
\hline $\begin{array}{l}\text { Escolaridade } \\
\text { Fundamental incompleto } \\
\text { Fundamental completo } \\
\text { Médio incompleto } \\
\text { Médio completo } \\
\text { Superior incompleto } \\
\text { Superior completo }\end{array}$ & $\begin{array}{l}46 \\
08 \\
06 \\
13 \\
00 \\
02\end{array}$ & $\begin{array}{l}61,3 \\
10,7 \\
8,0 \\
17,3 \\
0,0 \\
2,7\end{array}$ \\
\hline $\begin{array}{l}\text { Raça/Cor } \\
\text { Branca } \\
\text { Parda } \\
\text { Negra } \\
\text { Outra }\end{array}$ & $\begin{array}{l}04 \\
57 \\
09 \\
05\end{array}$ & $\begin{array}{l}5,3 \\
76,0 \\
12,0 \\
6,7\end{array}$ \\
\hline $\begin{array}{l}\text { Renda familiar mensal (salário mínimo) } \\
\text { Até } 1 \text { salário } \\
\text { 1-3 salários }\end{array}$ & $\begin{array}{l}74 \\
01\end{array}$ & $\begin{array}{l}98,7 \\
1,3\end{array}$ \\
\hline
\end{tabular}

\begin{tabular}{lllllll}
\hline Hygeia & Uberlândia - MG & v. 18 & 2022 & p. 29-43 & Página 32
\end{tabular}


Soroprevalência de infecções e riscos ocupacionais relacionados aos catadores de resíduos sólidos do extremo norte do Brasil
Raphael Barros Rocha João Victor Satrapa Silva Áurea Sérgia da Silva Macêdo Jamilla Karla Corrêa Reis Wagner do Carmo Costa

Ana lara Costa Ferreira Leila Braga Ribeiro Fabiana Nakashima

Bruna Kempfer Bassoli Bianca Jorge Sequeira

\begin{tabular}{l|l|l}
\hline \multicolumn{1}{c|}{ Variável } & $\begin{array}{c}\text { Frequência } \\
\text { Absoluta (n) }\end{array}$ & $\begin{array}{c}\text { Frequência } \\
\text { Relativa (\%) }\end{array}$ \\
\hline Ter Religião & 65 & \\
Sim & 10 & 86,7 \\
Não & 59 & 13,3 \\
\hline Filhos & 16 & 78,7 \\
Sim & & 21,3 \\
Não & 06 & \\
\hline Número de Filhos & 06 & 10,2 \\
01 & 10 & 10,2 \\
02 & 10 & 16,9 \\
03 & 07 & 16,9 \\
04 & 08 & 11,9 \\
05 & 04 & 13,5 \\
06 & 04 & 6,8 \\
07 & 01 & 6,8 \\
08 & 00 & 1,7 \\
09 & 02 & 00 \\
10 & 01 & 3,4 \\
11 & & 1,7 \\
Não respondeu & 20 & \\
\hline Tempo de trabalho como catador & 54 & 26,7 \\
Até 3 anos & 01 & 72,0 \\
Mais de 3 anos & & 1,3 \\
Não sabe responder & & \\
\hline
\end{tabular}

De um universo de 75 participantes avaliados, 03 indivíduos (prevalência de 4,0\%) apresentaram resultado positivo para infecções consideradas sexualmente transmissíveis, que podem também ser transmitidas por meio de sangue contaminado (Tabela 2). Dentre os participantes reagentes, 03 $(4,0 \%)$ apresentaram sífilis. Nenhum participante foi diagnosticado com HIV 1 e 2 ou Hepatites B e C. Convém ressaltar que nenhum dos participantes diagnosticados, no momento do estudo, tinha conhecimento de que estava contaminado.

Tabela 2 - Diagnóstico de infecções entre os catadores de resíduos sólidos vinculados às cooperativas de reciclagem Global e Terra Viva, Boa Vista, Roraima.

\begin{tabular}{c|c|c}
\hline Infecção Sexualmente Transmissível & Resultado Reagente & $\begin{array}{c}\text { Resultado Não } \\
\text { Reagente }\end{array}$ \\
\hline HIV/AIDS & $00(0,0 \%)$ & $75(100,0 \%)$ \\
\hline Sífilis & $03(4,0 \%)$ & $72(96,0 \%)$ \\
\hline Hepatite B & $00(0,0 \%)$ & $75(100,0 \%)$ \\
\hline Hepatite C & $00(0,0 \%)$ & $75(100,0 \%)$ \\
\hline
\end{tabular}

Dentre os participantes reagentes para sífilis, 01 era homem, pertencente a faixaria de 29 a 39 anos e 02 eram mulheres, a primeira tinha entre 40 e 49 anos e a segunda entre 50 e 59 anos.

Com relação ao perfil ocupacional dos catadores avaliados (Tabela 3), 93,3\% deles trabalha entre 20 e 40 horas semanalmente, sendo os dias mais comuns de trabalho, de segunda a sábado (33 participantes/44,0\%) e de segunda a sexta-feira (27 participantes/36,0\%). Nove participantes $(12,0 \%)$ relataram trabalharem de segunda a domingo, ou seja, sem nenhum dia de descanso semanal.

A grande maioria dos participantes (61 participantes/81,3\%) faz jornada de trabalho partida, ou seja, dividida entre manhã e tarde com intervalo para o almoço e $68(90,7 \%)$ não contribuem para nenhum tipo de aposentadoria ou plano de seguridade social. Com relação ao contrato de trabalho, 58 participantes $(77,3 \%)$ afirmaram a inexistência de um contrato escrito, sendo o vínculo com o trabalho

$\begin{array}{lllllll}\text { Hygeia } & \text { Uberlândia - MG } & \text { v. } 18 & 2022 & \text { p. 29-43 } & \text { Página } & 33\end{array}$


Soroprevalência de infecções e riscos ocupacionais relacionados aos catadores de resíduos sólidos do extremo norte do Brasil
Raphael Barros Rocha João Victor Satrapa Silva Áurea Sérgia da Silva Macêdo Jamilla Karla Corrêa Reis Wagner do Carmo Costa Ana lara Costa Ferreira Leila Braga Ribeiro

Fabiana Nakashima

Bruna Kempfer Bassoli

Bianca Jorge Sequeira

estabelecido apenas verbalmente. Além do trabalho como catador de resíduos sólidos, somente 05 pessoas $(6,6 \%)$ trabalham habitualmente em outros serviços.

Quando questionados se podiam tirar férias sem problemas $58,7 \%$ dos catadores afirmou que sim e sobre poder tirar licença médica esse percentual caiu para $41,3 \%$.

Tabela 3 - Perfil Ocupacional dos catadores de resíduos sólidos vinculados às cooperativas de reciclagem Global e Terra Viva, Boa Vista, Roraima.

\begin{tabular}{|c|c|c|}
\hline Variável & $\begin{array}{l}\text { Frequência } \\
\text { Absoluta (n) }\end{array}$ & $\begin{array}{l}\text { Frequência } \\
\text { Relativa (\%) }\end{array}$ \\
\hline $\begin{array}{l}\text { Horas trabalhadas por semana } \\
\text { Até } 20 \text { horas } \\
\text { Entre } 20 \text { e } 40 \text { horas }\end{array}$ & $\begin{array}{l}05 \\
70\end{array}$ & $\begin{array}{l}6,7 \\
93,3\end{array}$ \\
\hline $\begin{array}{l}\text { Dias da semana trabalhados } \\
\text { Dias irregulares } \\
\text { Segunda a sexta-feira } \\
\text { Segunda a sábado } \\
\text { Segunda a domingo }\end{array}$ & $\begin{array}{l}06 \\
27 \\
33 \\
09\end{array}$ & $\begin{array}{l}8,0 \\
36,0 \\
44,0 \\
12,0\end{array}$ \\
\hline $\begin{array}{l}\text { Jornada de trabalho habitual } \\
\text { Irregular } \\
\text { Jornada partida (manhã e tarde) } \\
\text { Jornada contínua (entre } 8 \text { h00 e 15h00) } \\
\text { Jornada noturna }\end{array}$ & $\begin{array}{l}02 \\
61 \\
08 \\
04\end{array}$ & $\begin{array}{l}2,7 \\
81,3 \\
10,7 \\
5,3\end{array}$ \\
\hline $\begin{array}{l}\text { Contribuição para aposentadoria ou seguridade social } \\
\text { Sim } \\
\text { Não }\end{array}$ & $\begin{array}{l}07 \\
68\end{array}$ & $\begin{array}{l}9,3 \\
90,7\end{array}$ \\
\hline $\begin{array}{l}\text { Pode tirar férias sem problemas } \\
\text { Sim } \\
\text { Não }\end{array}$ & $\begin{array}{l}31 \\
44\end{array}$ & $\begin{array}{l}41,3 \\
58,7\end{array}$ \\
\hline $\begin{array}{l}\text { Pode tirar licença médica sem problema } \\
\text { Sim } \\
\text { Não }\end{array}$ & $\begin{array}{l}60 \\
15\end{array}$ & $\begin{array}{l}80,0 \\
20,0\end{array}$ \\
\hline $\begin{array}{l}\text { Visita o médico quando precisa sem problema } \\
\text { Sim } \\
\text { Não }\end{array}$ & $\begin{array}{l}65 \\
10\end{array}$ & $\begin{array}{l}86,7 \\
13,3\end{array}$ \\
\hline $\begin{array}{l}\text { Tipo de contrato no seu trabalho } \\
\text { Escrito } \\
\text { Oral } \\
\text { Não respondeu }\end{array}$ & $\begin{array}{l}07 \\
58 \\
10\end{array}$ & $\begin{array}{l}9,4 \\
77,3 \\
13,3\end{array}$ \\
\hline $\begin{array}{l}\text { Além do trabalho como catador, possui outro trabalho } \\
\text { Não } \\
\text { Sim, mas ocasionalmente } \\
\text { Sim, habitualmente } \\
\text { Sim, trabalho por temporada }\end{array}$ & $\begin{array}{l}51 \\
17 \\
05 \\
02\end{array}$ & $\begin{array}{l}68,0 \\
22,7 \\
6,6 \\
2,7\end{array}$ \\
\hline
\end{tabular}

Quando avaliado o perfil de exposição aos riscos ocupacionais dos participantes do estudo (Tabela 4), utilizando para isto uma escala Likert de frequência (nunca, muito poucas vezes, algumas vezes, muitas vezes e sempre), foram observados os seguintes resultados agrupando as respostas que indicavam maior frequência de ocorrência do evento (algumas vezes, muitas vezes e sempre): trabalho em solos ou pisos não estáveis ou irregulares (58,7\%); trabalho em proximidade a buracos ou desníveis $(57,3 \%)$; utilização de equipamentos ou instrumentos que poderiam provocar danos como cortes, lacerações ou amputações (42,7\%); exposição à ruídos de alto volume $(57,3 \%)$; exposição à luz (radiação) solar (70,7\%); manipulação ou contato com substâncias químicas nocivas $(36,0 \%)$; inspiração de substâncias químicas em gases ou aerossol (38,6\%), manipulação ou contato

$\begin{array}{lllllll}\text { Hygeia } & \text { Uberlândia - MG } & \text { v. } 18 & 2022 & \text { p. 29-43 } & \text { Página } & 34\end{array}$


Soroprevalência de infecções e riscos ocupacionais relacionados aos catadores de resíduos sólidos do extremo norte do Brasil
Raphael Barros Rocha João Victor Satrapa Silva Áurea Sérgia da Silva Macêdo Jamilla Karla Corrêa Reis Wagner do Carmo Costa Ana lara Costa Ferreira Leila Braga Ribeiro

Fabiana Nakashima

Bruna Kempfer Bassoli

Bianca Jorge Sequeira

com materiais contaminados (32,0\%); realização de tarefas em posturas incômodas $(76,0 \%)$ e transporte ou levantamento de cargas ou objetos pesados $(72,1 \%)$.

Tabela 4 - Perfil de exposição à riscos ocupacionais dos catadores de resíduos sólidos vinculados às cooperativas de reciclagem Global e Terra Viva, Boa Vista, Roraima.

\begin{tabular}{|c|c|c|}
\hline Variável & $\begin{array}{l}\text { Frequência } \\
\text { Absoluta (n) }\end{array}$ & $\begin{array}{l}\text { Frequência } \\
\text { Relativa (\%) }\end{array}$ \\
\hline $\begin{array}{l}\text { Trabalha em solos ou pisos não-estáveis, irregulares ou } \\
\text { escorregadios, que podem provocar quedas. } \\
\text { Nunca } \\
\text { Muito poucas vezes } \\
\text { Algumas vezes } \\
\text { Muitas vezes } \\
\text { Sempre } \\
\text { Não sei }\end{array}$ & $\begin{array}{l}21 \\
08 \\
22 \\
08 \\
14 \\
02\end{array}$ & $\begin{array}{l}28,0 \\
10,6 \\
29,3 \\
10,6 \\
18,8 \\
2,7\end{array}$ \\
\hline $\begin{array}{l}\text { Trabalha próximo a buracos, escadas ou desníveis, que podem } \\
\text { provocar quedas } \\
\text { Nunca } \\
\text { Muito poucas vezes } \\
\text { Algumas vezes } \\
\text { Muitas vezes } \\
\text { Sempre }\end{array}$ & $\begin{array}{l}26 \\
06 \\
18 \\
10 \\
15\end{array}$ & $\begin{array}{l}34,7 \\
8,0 \\
24,0 \\
13,3 \\
20,0\end{array}$ \\
\hline $\begin{array}{l}\text { Utiliza equipamentos, ferramentas ou máquinas que podem } \\
\text { provocar danos } \\
\text { Nunca } \\
\text { Muito poucas vezes } \\
\text { Algumas vezes } \\
\text { Muitas vezes } \\
\text { Sempre }\end{array}$ & $\begin{array}{l}34 \\
09 \\
12 \\
05 \\
15\end{array}$ & $\begin{array}{l}45,3 \\
12,0 \\
16,0 \\
6,7 \\
20,0\end{array}$ \\
\hline $\begin{array}{l}\text { Está exposto a um nível de ruído que o obriga a elevar a voz } \\
\text { para conversar com outra pessoa } \\
\text { Nunca } \\
\text { Muito poucas vezes } \\
\text { Algumas vezes } \\
\text { Muitas vezes } \\
\text { Sempre }\end{array}$ & $\begin{array}{l}26 \\
06 \\
21 \\
07 \\
15 \\
\end{array}$ & $\begin{array}{l}34,7 \\
8,0 \\
28,0 \\
9,3 \\
20,0\end{array}$ \\
\hline $\begin{array}{l}\text { Está exposto à luz (radiação) solar? } \\
\text { Nunca } \\
\text { Muito poucas vezes } \\
\text { Algumas vezes } \\
\text { Muitas vezes } \\
\text { Sempre }\end{array}$ & $\begin{array}{l}18 \\
04 \\
20 \\
12 \\
21 \\
\end{array}$ & $\begin{array}{l}24,0 \\
5,3 \\
26,7 \\
16,0 \\
28,0\end{array}$ \\
\hline $\begin{array}{l}\text { Manipula ou tem contato com substâncias químicas nocivas } \\
\text { Nunca } \\
\text { Muito poucas vezes } \\
\text { Algumas vezes } \\
\text { Muitas vezes } \\
\text { Sempre }\end{array}$ & $\begin{array}{l}38 \\
10 \\
15 \\
03 \\
09 \\
\end{array}$ & $\begin{array}{l}50,7 \\
13,3 \\
20,0 \\
4,0 \\
12,0\end{array}$ \\
\hline $\begin{array}{l}\text { Respira substâncias químicas em forma de pó, vapores, gases } \\
\text { ou aerossol? } \\
\text { Nunca } \\
\text { Muito poucas vezes } \\
\text { Algumas vezes } \\
\text { Muitas vezes }\end{array}$ & $\begin{array}{l}38 \\
08 \\
12 \\
05 \\
\end{array}$ & $\begin{array}{l}50,7 \\
10,7 \\
16,0 \\
6,6\end{array}$ \\
\hline
\end{tabular}


Soroprevalência de infecções e riscos ocupacionais relacionados aos catadores de resíduos sólidos do extremo norte do Brasil
Raphael Barros Rocha João Victor Satrapa Silva Áurea Sérgia da Silva Macêdo Jamilla Karla Corrêa Reis Wagner do Carmo Costa Ana lara Costa Ferreira Leila Braga Ribeiro Fabiana Nakashima Bruna Kempfer Bassoli Bianca Jorge Sequeira

\begin{tabular}{l|l|l}
\hline \multicolumn{1}{c|}{ Variável } & $\begin{array}{c}\text { Frequência } \\
\text { Absoluta (n) }\end{array}$ & $\begin{array}{l}\text { Frequência } \\
\text { Relativa (\%) }\end{array}$ \\
\hline Sempre & 12 & 16,0 \\
\hline Manipula ou está em contato com materiais, animais ou pessoas & & \\
que podem estar infectados & 45 & 60,0 \\
Nunca & 06 & 8,0 \\
Muito poucas vezes & 14 & 18,7 \\
Algumas vezes & 00 & 0,0 \\
Muitas vezes & 10 & 13,3 \\
Sempre & & \\
\hline Realiza tarefa que o obriga a manter posturas incômodas & 12 \\
Nunca & 06 & 16,0 \\
Muito poucas vezes & 15 & 8,0 \\
Algumas vezes & 15 & 20,0 \\
Muitas vezes & 27 & 20,0 \\
Sempre & & 36,0 \\
\hline Levanta, transporta ou arrasta cargas ou objetos pesados & 14 & \\
Nunca & 07 & 18,7 \\
Muito poucas vezes & 17 & 9,2 \\
Algumas vezes & 14 & 22,7 \\
Muitas vezes & 23 & 18,7 \\
Sempre & & 30,7 \\
\hline Tem que trabalhar muito rápido & 23 & 30,7 \\
Nunca & 17 & 22,7 \\
Muito poucas vezes & 21 & 28,0 \\
Algumas vezes & 06 & 8,0 \\
Muitas vezes & 08 & 10,6 \\
Sempre &
\end{tabular}

Após a avaliação da exposição aos riscos, foi verificada a percepção que os catadores tinham sobre sua atividade laboral, utilizando a mesma escala Likert de frequência. Foram observados os seguintes achados, também agrupando as respostas que indicavam maior frequência de ocorrência do evento (algumas vezes, muitas vezes e sempre): $46 \%$ dos participantes afirmou ter que trabalhar muito rápido; $40,0 \%$ alegou que precisava controlar muitas coisas de uma vez; $65,4 \%$ relatou que seu trabalho permitia a aplicação de seus conhecimentos e habilidades; $54,7 \%$ disse que podia influenciar na quantidade de trabalho que lhe era determinada e $85,3 \%$ recebiam a ajuda dos colegas quando necessitavam para executar as atividades laborais.

Ao serem questionados se consideravam o salário recebido justo em relação ao seu desempenho no trabalho $52,0 \%$ respondeu nunca, seguidos de $13,3 \%$ que respondeu muito poucas vezes e ao responderem a pergunta que abordava sua preocupação em ficar desempregado e ter que arrumar um outro emprego, $73,4 \%$ dos participantes respondeu estar bastante ou muito preocupado (Tabela $5)$. 
Soroprevalência de infecções e riscos ocupacionais relacionados aos catadores de resíduos sólidos do extremo norte do Brasil
Raphael Barros Rocha João Victor Satrapa Silva Áurea Sérgia da Silva Macêdo Jamilla Karla Corrêa Reis Wagner do Carmo Costa Ana lara Costa Ferreira Leila Braga Ribeiro Fabiana Nakashima Bruna Kempfer Bassoli Bianca Jorge Sequeira

Tabela 5 - Percepção dos catadores de resíduos sólidos vinculados às cooperativas de reciclagem Global e Terra Viva, Boa Vista, Roraima, acerca da sua atividade laboral.

\begin{tabular}{l|l|l}
\hline \multicolumn{1}{c|}{ Variável } & $\begin{array}{c}\text { Frequência } \\
\text { Absoluta (n) }\end{array}$ & $\begin{array}{l}\text { Frequência } \\
\text { Relativa (\%) }\end{array}$ \\
\hline Seu trabalho exige que tenha que controlar muitas coisas de & & \\
uma vez & & \\
Nunca & 32 & 42,7 \\
Muito poucas vezes & 12 & 16,0 \\
Algumas vezes & 17 & 22,7 \\
Muitas vezes & 07 & 9,3 \\
Sempre & 06 & 8,0 \\
Não sei & 01 & 1,3 \\
\hline Seu trabalho exige que esconda suas emoções ou sentimentos & & \\
Nunca & 31 & 41,3 \\
Muito poucas vezes & 15 & 20,0 \\
Algumas vezes & 15 & 20,0 \\
Muitas vezes & 08 & 10,7 \\
Sempre & 06 & 8,0 \\
\hline Seu trabalho permite que você aplique seus conhecimentos e & & \\
habilidades & & 12,0 \\
Nunca & 09 & 20,0 \\
Muito poucas vezes & 15 & 30,7 \\
Algumas vezes & 23 & 18,7 \\
Muitas vezes & 14 & 16,0 \\
Sempre & 12 & 2,6 \\
Não sei & 02 & \\
\hline Você pode influenciar na quantidade de trabalho que Ihe dão & & \\
Nunca & 21 & 28,0 \\
Muito poucas vezes & 13 & 17,3 \\
Algumas vezes & 21 & 28,0 \\
Muitas vezes & 13 & 17,3 \\
Sempre & 07 & 9,4 \\
\hline Você recebe ajuda dos colegas para realizar as tarefas & & \\
Nunca & 08 & 10,7 \\
Muito poucas vezes & 03 & 4,0 \\
Algumas vezes & 26 & 34,6 \\
Muitas vezes & 08 & 10,7 \\
Sempre & 30 & 40,0 \\
\hline Você considera seu salário justo & 39 & 52,0 \\
Nunca & 10 & 13,3 \\
Muito poucas vezes & 11 & 14,7 \\
Algumas vezes & 05 & 6,7 \\
Muitas vezes & 10 & 13,3 \\
Sempre & & \\
\hline Até que ponto você fica preocupado em perder o emprego & 18 & 24,0 \\
Bastante preocupado & 37 \\
Muito preocupado & 09 & 07 \\
Mais ou menos preocupado & 03 & 01 \\
Pouco preocupado & & \\
Nada preocupado & & \\
Não sei & & \\
\hline
\end{tabular}

\begin{tabular}{lllllll}
\hline Hygeia & Uberlândia - MG & v. 18 & 2022 & p. 29-43 & Página & 37
\end{tabular}


Soroprevalência de infecções e riscos ocupacionais relacionados aos catadores de resíduos sólidos do extremo norte do Brasil
Raphael Barros Rocha

João Victor Satrapa Silva Áurea Sérgia da Silva Macêdo Jamilla Karla Corrêa Reis Wagner do Carmo Costa

Ana lara Costa Ferreira Leila Braga Ribeiro

Fabiana Nakashima

Bruna Kempfer Bassoli

Bianca Jorge Sequeira

Evidenciou-se associação estatisticamente significativa entre ser mulher e trabalhar há mais tempo na catação de resíduos sólidos $(p=0,03)$ e entre ter menor escolaridade e trabalhar há mais tempo como catador $(p=0,001)$. Não foi observada associação entre o gênero e a preocupação de perder o emprego $(p=0,37)$, a escolaridade e a preocupação de perder o emprego $(p=0,51)$, o gênero e a manipulação ou contato com resíduos contaminados $(p=0,71)$, o gênero e o transporte ou carregamento de cargas pesadas $(p=0,26)$, nem entre 0 gênero e a utilização de instrumentos ou equipamentos que poderia provocar danos $(p=0,90)$. Não foi possível testar a associação entre as variáveis e o desfecho ter infecção, pois o número de participante com diagnóstico positivo foi pequeno (03 participantes), inviabilizando assim a realização do teste qui-quadrado.

\section{DISCUSSÃO}

A atividade de catar lixo não constitui algo novo, sendo há muito tempo um trabalho comum, uma estratégia de sobrevivência desenvolvida entre uma parcela socioeconomicamente excluída do Brasil e em outros países do mundo (LEITE; WIRTH; CHERFEM, 2015).

Durante a visita às cooperativas de reciclagem de resíduos sólidos, observou-se rotineiramente a presença de crianças, filhos dos catadores, auxiliando na rotina de trabalho dos pais. Este achado corrobora as afirmações de Costa e Pato (2010) ao defenderem que os processos de exclusão se iniciam ainda na infância, quando algumas crianças já convivem com a realidade da atividade laboral futura, além dos percalços que essa atividade Ihes trará, por serem filhos de catadores. Os pais ensinam seus filhos a entrar no processo de catação, por ser uma atividade informal e distante dos órgãos de fiscalização, fato que caracteriza mais uma dimensão de vulnerabilidade desse trabalho (ARAGÃO-NETO; GOMES, 2017).

Ao avaliar os dados sociodemográficos dos 75 participantes, evidencia-se que a maioria pertence a faixa etária de 40 a 49 anos (22 participantes/29,3\%), sendo a média de idade dos catadores de 38,3 anos. Este resultado é reforçado por vários outros estudos que apontam que a maioria desses trabalhadores têm entre 40 e 50 anos (JESUS et al., 2012; SILVA et al., 2017). De acordo com Gomes (2015), apesar da divergência de dados acerca da quantidade global de catadores no Brasil, pesquisas do IPEA (2013) apontam que a média de idade desses trabalhadores é de 39,4 anos. O presente estudo diverge dos dados encontrados por Neves et al. (2017) e Silva (2016) ao apontarem a faixa etária de 25 a 39 anos como a mais prevalente entre os catadores.

O registro da faixa etária é relevante por demonstrar que os catadores não se encontram temporariamente nessa atividade, uma vez que estão no auge de sua idade produtiva (GOMES, 2015). Silva (2016) complementa afirmando que a distribuição etária apontada na maioria das pesquisas evidencia que além da grande maioria dos entrevistados estar na fase mais produtiva da vida, os mais jovens nunca estiveram inseridos no mercado de trabalho formal e/ou tem a catação como primeira experiência de trabalho, fato que é um reflexo da exclusão social em que vivem.

Quanto ao gênero, a maioria dos participantes deste estudo são mulheres $(68,0 \%)$. Este resultado corrobora com várias outras pesquisas que apontam o predomínio de mulheres atuando como catadoras nas cooperativas de reciclagem (TEIXEIRA, 2015; PEREIRA et al., 2016; NEVES et al., 2017; SILVEIRA; SOUSA; TEIXEIRA, 2019). Esses dados são reforçados por Bittencourt e Muttoni (2014) em estudo realizado com catadores do município de Porto Alegre. O predomínio de participantes do gênero feminino, pode sugerir que as mulheres se sentem mais seguras trabalhando nas cooperativas, pois estão menos sujeitas à violência e as intempéries das ruas (BRAZ et al., 2014). Por outro lado, Jesus et al. (2012) e Silva (2016), evidenciam em seu estudo o predomínio de catadores homens (71,9\%), divergindo assim do presente estudo. Para Hoefel et al. (2013), a presença masculina é predominante no trabalho informal de catação de materiais porque as mulheres catadoras possuem outras atribuições, como cuidar do lar e da família.

Quanto a escolaridade, percebe-se que a maioria dos participantes tem apenas o ensino fundamental incompleto (46 participantes/61,3\%), sendo evidenciada associação significativa entre ter menor escolaridade e trabalhar há mais tempo como catador $(p=0,001)$. Essa baixa escolaridade é também comumente observada em diversos outros estudos realizados com os catadores de resíduos sólidos,

$\begin{array}{lllllll}\text { Hygeia } & \text { Uberlândia - MG } & \text { v. 18 } & 2022 & \text { p. 29-43 } & \text { Página } & 38\end{array}$


Soroprevalência de infecções e riscos ocupacionais relacionados aos catadores de resíduos sólidos do extremo norte do Brasil
Raphael Barros Rocha

João Victor Satrapa Silva Áurea Sérgia da Silva Macêdo Jamilla Karla Corrêa Reis Wagner do Carmo Costa

Ana lara Costa Ferreira Leila Braga Ribeiro

Fabiana Nakashima

Bruna Kempfer Bassoli

Bianca Jorge Sequeira

os quais apontam o nível fundamental incompleto como o mais prevalente, variando entre $70,0 \%$ e $80,0 \%$ do universo amostral (JESUS et al., 2012; SILVA et al., 2017; NEVES et al., 2017; PEREIRA et al., 2016; GOMES, 2015). Talvez, a baixa escolaridade seja explicada pelo fato de que vários deles iniciam a atividade de catação ainda crianças, não tendo a chance de se dedicar aos estudos, haja visto terem que ajudar os pais no sustento da família.

No tocante a renda familiar mensal, a renda de até 1 salário mínimo foi a mais prevalente $(98,7 \%)$ e apenas um participante do estudo relatou receber entre 1 e 3 salários mínimos. Por tratar-se de pessoas que vivenciam o anonimato e o abandono social, sem direito a políticas públicas protecionistas, a baixa renda é evidenciada em diversos estudos, confirmando assim mais uma dimensão de vulnerabilidade vivenciada por esses profissionais (NEVES et al., 2017; SILVA, 2016; TEIXEIRA, 2015). No censo de 2010, a média geral de remuneração dos catadores foi de apenas $R \$$ 571,56 , caindo para $R \$ 459,34$ na região nordeste (GOMES, 2015).

Dentre aqueles que afirmaram ter filhos, foi observada a média de 4,54 filhos por participante. Média considerada alta, levando-se em consideração a baixa renda familiar. Jesus et al. (2012) encontraram em seus estudos que $49 \%$ dos catadores possuía até 03 filhos. Uma característica frequente das populações negligenciadas é um grande quantitativo de filhos, fato que se deve muitas vezes ao desconhecimento das políticas públicas de planejamento familiar, situação reforçada pela baixa escolaridade e nível de informação.

Ao serem questionados sobre o tempo de atuação como catadores, tem-se que a grande maioria $(72,0 \%)$ possuía essa ocupação há mais de 3 anos, tendo iniciado sua atividade na catação antes mesmo da criação das cooperativas, uma vez que a grande parte dos participantes do estudo atuava no lixão municipal antes de ser cooperativado. A média de trabalho dos participantes nessa atividade foi de 7,56 anos, sendo evidenciada associação estatisticamente significativa entre ser mulher e atuar há mais tempo como catadora $(p=0,03)$. Outros estudos apontam que é comum a longa permanência nesse tipo de ocupação, uma vez que a maioria dos catadores não têm perspectivas de conseguir uma outra atividade laboral, principalmente pelo baixo nível de escolaridade (NEVES et al., 2017; SILVEIRA; SOUSA; TEIXEIRA, 2019).

Considerando todo o cenário descrito, os catadores de materiais recicláveis são considerados um grupo populacional vulnerável e carecem de maior atenção do poder público, especialmente por parte sistema de saúde (JESUS et al., 2012).

Sabe-se que ao manipular o lixo, os catadores entram em contato com diversos microrganismos patogênicos, capazes de causar infecções, como vírus, fungos e bactérias. O processo de transmissão de doenças infectoparasitárias corresponde à lógica da tríade: agente etiológico, hospedeiro e ambiente. Nessa concepção, qualquer desequilíbrio em um desses fatores levaria ao processo de transmissão das doenças (BONITA; BEAGLEHOLE; KJELLSTRÖM, 2010). O ambiente é um dos principais fatores relacionados a transmissão de doenças infectocontagiosas, já que está intimamente relacionado com sua disseminação. Nesse aspecto, o conceito de ambiente se amplia para além do biológico, envolvendo também o ambiente político, ambiente cultural, ambiente social, ambiente físico e por fim ambiente laboral (BONITA; BEAGLEHOLE; KJELLSTRÖM, 2010).

Desta forma, dentre a população estudada, é comum a ocorrência de quadros infecciosos, adquiridos por meio do contato com lixo que pode conter fluidos orgânicos e instrumentos perfurocortantes contaminados com microrganismos como o Vírus da Imunodeficiência Adquirida (HIV), o Vírus da Hepatite B (HBV), Hepatite C (HCV) e com a bactéria Treponema pallidum, agente etiológico da sífilis (BRASIL, 2005). Vale ressaltar a inexistência de coleta seletiva de lixo em Roraima e consequentemente a ocorrência do descarte inadequado.

A prevalência de infecções consideradas sexualmente transmissíveis e que podem também ser transmitidas por meio de fluidos contaminados presentes no lixo, na amostra estudada foi de $4,0 \%$. Três participantes foram diagnosticados com sífilis. Não foi evidenciado nenhum caso de HIV e Hepatites B e C. Quanto aos danos à saúde, evidencia-se que os catadores estão constantemente expostos à riscos biológicos e físicos, acidentes com cortes, perfurações, queimaduras, dermatites intoxicações alimentares e doenças infecciosas e parasitárias (NEVES et al., 2017). Existe uma

$\begin{array}{lllllll}\text { Hygeia } & \text { Uberlândia - MG } & \text { v. } 18 & 2022 & \text { p. 29-43 } & \text { Página } & 39\end{array}$


Soroprevalência de infecções e riscos ocupacionais relacionados aos catadores de resíduos sólidos do extremo norte do Brasil
Raphael Barros Rocha

João Victor Satrapa Silva Áurea Sérgia da Silva Macêdo Jamilla Karla Corrêa Reis Wagner do Carmo Costa

Ana lara Costa Ferreira Leila Braga Ribeiro

Fabiana Nakashima

Bruna Kempfer Bassoli

Bianca Jorge Sequeira

realidade no tocante à saúde do trabalhador que a epidemiologia não alcança, seja por não cultivar a categoria trabalho como central em suas observações, seja por não assumir a dimensão requerida como um grave problema de saúde pública (VASCONCELLOS, 2018).

A ferramenta que traçou o perfil ocupacional dos catadores (Tabela 3), aponta que a maioria dos participantes $(68,0 \%)$ tem a catação como sua única fonte de renda, não possuindo assim um outro trabalho remunerado, fazendo uma jornada de trabalho de 8 horas diárias. Esses dados corroboram os resultados do estudo de Jesus et al. (2012) e Teixeira (2015) que apontaram que $57,3 \%$ e $59,0 \%$ dos catadores trabalhavam somente com a catação de materiais recicláveis, não possuindo assim nenhuma outra fonte de renda. No estudo de Silveira, Sousa e Teixeira (2019), a carga horária diária encontrada foi de 7 horas.

Além disso, no presente estudo, 68 pessoas $(90,7 \%)$ não contribuem para nenhum tipo de aposentadoria ou plano de seguridade social. Como a maioria das cooperativas não atinge um rendimento que permita a retirada de um salário mínimo para cada sócio, a contribuição previdenciária torna-se praticamente impossível (SANTOS, 2018). Esse resultado é confirmado por Silva (2016), que em sua pesquisa concluiu que nenhum participante tinha condições financeiras de contribuir para qualquer tipo de previdência ou plano de aposentadoria.

Com relação ao contrato de trabalho, 58 participantes $(77,3 \%)$ afirmaram a inexistência de um contrato escrito, sendo o vínculo com o trabalho estabelecido apenas verbalmente. Infelizmente, essa é a realidade vivenciada pela maioria dos catadores no Brasil, fato que gera insegurança e configura a frágil relação desses profissionais com o Estado.

Quanto ao perfil de exposição dos catadores à riscos à saúde (Tabela 4), a literatura mostra que os locais onde são armazenados resíduos sólidos descartados pelas populações são locais com alto potencial infectante, principalmente para aquelas pessoas que estão em contato íntimo e duradouro (SILVA et al., 2017).

A utilização de equipamentos que poderiam provocar danos $(42,7 \%)$, a exposição à luz solar que poderia contribuir para a ocorrência de câncer de pele ou insolação $(70,7 \%)$, uma vez que Roraima é um dos estados brasileiros com maior incidência de luz solar, a realização de tarefas em posturas incômodas $(76,0 \%)$ e a manipulação de materiais contaminados $(32,0 \%)$, bem como o transporte de objetos pesados $(72,1 \%)$ são ocorrências que afetam diretamente o processo saúde-doença na vida desses trabalhadores. Mesmo que o trabalhador não perceba, a ocupação de catador é uma atividade desgastante para o ser humano e pode acarretar agravos à saúde (JESUS et al., 2012). Um resultado que chama atenção é o fato de apenas $32,0 \%$ dos trabalhadores responder que manipula materiais contaminados. Provavelmente, esse baixo percentual se deve ao fato de os mesmos não terem a real noção do que são microrganismos e do quanto estes podem estar presentes no lixo e em matérias em decomposição. Essa reposta pode impactar diretamente no grau de exposição aos riscos que os catadores se submetem, fazendo com que os mesmos não tomem as devidas precauções durante o processo de manipulação.

Os catadores contraem diversos tipos de doenças relacionadas ao trabalho: hérnia de disco, doenças reumáticas, problemas do sistema muscular, problemas do sistema articular. Os catadores relatam diferentes agravos à saúde como furadas de agulhas e dores musculares em várias partes do corpo relacionadas a movimentos repetitivos e diferentes esforços físicos para realização de seu trabalho diário (SILVA, 2016). Neves et al. (2017) apontam que em relação aos relatos dos catadores sobre acometimentos por doenças relacionadas ao trabalho, 17,9\% relataram dor, 5,1\% alergias e 5,1\% acidentes durante o manuseio dos resíduos. Já Dobrachinski e Dobrachinski (2016) relatam que após um dia de trabalho, os catadores se queixam de dores musculares, na coluna, cefaleia e um extremo cansaço devido à exposição ao sol e esforços físicos.

Agrava a situação, ter sido observado no presente estudo, o fato de $100 \%$ dos entrevistados não utilizar nenhum equipamento de proteção individual (EPI). Eles alegam que além de não terem dinheiro para comprá-los, sua utilização dificultaria o desempenho no trabalho e a sensibilidade das mãos. Durante as visitas às cooperativas, foi possível verificar que a maioria dos trabalhadores estava usando sandália de dedo, bermuda e camiseta tipo regata ou manga curta, sem nenhum tipo

$\begin{array}{lllllll}\text { Hygeia } & \text { Uberlândia - MG } & \text { v. 18 } & 2022 & \text { p. 29-43 } & \text { Página } 40\end{array}$


Soroprevalência de infecções e riscos ocupacionais relacionados aos catadores de resíduos sólidos do extremo norte do Brasil
Raphael Barros Rocha

João Victor Satrapa Silva Áurea Sérgia da Silva Macêdo Jamilla Karla Corrêa Reis Wagner do Carmo Costa

Ana lara Costa Ferreira Leila Braga Ribeiro

Fabiana Nakashima

Bruna Kempfer Bassoli

Bianca Jorge Sequeira

de EPI. A presença de animais domésticos em contato com o lixo e os trabalhadores também foi rotineira. De acordo com Hoefel et al. (2013) os catadores, em sua maioria, já sofreram algum tipo de acidente e a exposição aos riscos aumenta com o fato de não utilizarem equipamentos de proteção individual (EPIs). Pereira et al. (2016) e Neves et al. (2017) relatam que a não utilização de EPIs e o uso de vestimentas inadequadas também foram observados em seus estudos.

Desta forma, para prevenir tais agravos é preciso compreender as atividades de trabalho e seus determinantes, tanto os proximais quanto os associados à organização do trabalho (JACKSON FILHO et al., 2018).

Por fim, observa-se que apesar dos riscos e da baixa renda atrelados ao trabalho de catador, a maioria dos participantes $(73,4 \%)$ relatou ser bastante ou muito preocupado com a possibilidade de perder seu emprego. A baixa escolaridade atrelada à não formalização do trabalho talvez possam explicar a falta de comprometimento e a acomodação com a situação. Por estarem em uma situação de autoemprego (TEIXEIRA, 2015; ROLIM; TEIXEIRA; FERNANDES, 2015).

\section{CONCLUSÃO}

Conclui-se que a prevalência de infecções que podem ser sexualmente transmissíveis ou transmissíveis por contato com material contaminado por fluidos orgânicos foi de $4 \%$ na amostra analisada, de forma que três participantes apresentaram diagnóstico positivo para sífilis. Trata-se de um resultado bastante significativo, uma vez que são infecções evitáveis a partir da adoção de comportamentos preventivos. Houve associação estatisticamente significativa entre trabalhar há mais tempo como catador e ser mulher e ter baixa escolaridade. Verificou-se a constante exposição dos trabalhadores à riscos ocupacionais ergonômicos, químicos e biológicos e a não utilização de EPIs como um agravante à essa exposição.

Faz-se necessária a criação de políticas públicas protetivas, como a possibilidade de aposentadoria diferenciada, que atendam às necessidades dessa classe de trabalhadores e a implementação de um processo de educação permanente que aborde os riscos ocupacionais e a importância da utilização correta dos EPIs.

\section{REFERÊNCIAS}

ARAGÃO NETO, F.A.; GOMES, A.V.M. Dignidade humana, desenvolvimento e o trabalho dos catadores de resíduos sólidos. Direito e Desenvolvimento. v. 7, n. 2, p. 189-207. 2017. https://doi.org/10.26843/direitoedesenvolvimento.v7i2.324

BITTENCOURT, D.C.; MUTTONI, S.M.P. Perfil nutricional dos trabalhadores de cooperativas de reciclagem de resíduos sólidos da região metropolitana de Porto Alegre. Revista CIPPUSUNILASALLE. v. 3, n. 1, p. 149-165. 2014.

BONITA, R.; BEAGLEHOLE.; KJELLSTRÖM, T. Epidemiologia Básica. São Paulo, Santos, 2010.

BRASIL. Ministério da Saúde, Secretaria de Vigilância em Saúde, Departamento de Vigilância Epidemiológica. Hepatites virais: o Brasil está atento. Brasília: Ministério da Saúde, 2005.

BRAZ, R.F.S.; BISPO, C.S.; COLOMBO, C.R.; MEDEIROS, M.F.S.; SILVA, J.C.S.; TEIXEIRA, M.T.C.; SARTHOUR, S.A.; SOUZA, M.F. Estudos sobre os aspectos socioeconômicos dos catadores de resíduos recicláveis organizados em cooperativas na cidade de Natal-RN. Revista Eletrônica do Mestrado em Educação Ambiental. Ed. Especial Impressa, p. 147-159. 2014.

COSTA, C.M.; PATO, C. A trajetória de vida dos catadores de materiais recicláveis. RBEC. v.1, n.1, p. 80-96. 2010.

DOBRACHINSKI, L.; DOBRACHINSKI, M. M. M. Condições de vida, trabalho e saúde dos catadores de materiais recicláveis do lixão de um município do Oeste da Bahia. Hígia. v. 1, n. 1, p. 18-45. 2016.

\begin{tabular}{lllllll}
\hline Hygeia & Uberlândia - MG & v. 18 & 2022 & p. 29-43 & Página & 41
\end{tabular}


Soroprevalência de infecções e riscos ocupacionais relacionados aos catadores de resíduos sólidos do extremo norte do Brasil
Raphael Barros Rocha João Victor Satrapa Silva Áurea Sérgia da Silva Macêdo Jamilla Karla Corrêa Reis Wagner do Carmo Costa

Ana lara Costa Ferreira Leila Braga Ribeiro Fabiana Nakashima Bruna Kempfer Bassoli Bianca Jorge Sequeira

GALON, T.; MARZIALE, M. H. P. Condições de trabalho e saúde de catadores de materiais recicláveis na américa Latina: uma revisão de escopo. In: PEREIRA, C. J.; GOES, F. L. (orgs.). Catadores de materiais recicláveis: um encontro nacional. Rio de Janeiro: Ipea, 2016.

GOMES, A.V.M. Regulação de formas inaceitáveis de trabalho: o caso da proteção legal dos catadores de lixo no Brasil. São Paulo: LTR, 2015.

HOEFELL, M.G.; CARNEIRO, F.F.; SANTOS, L.M.P.; GUBERT, M.B.; SANTOS, E.M.A.W. Acidentes de trabalho e condições de vida de catadores de resíduos sólidos recicláveis no lixão do Distrito Federal. Rev. Bras. Epidemiol. v. 16, n. 3, p. 764-785. 2013. https://doi.org/10.1590/S1415$\underline{790 \times 2013000300020}$

JACKSON FILHO, J.M.; PINA, J.A.; VILELA, R.G.A.; SOUZA, K.R. Desafios para a intervenção em saúde do trabalhador. Rev Bras Saude Ocup. v. 43, supl I, p. 01-07.2018. https://doi.org/10.1590/2317-6369ap0141218

JESUS, M.C.P.; SANTOS, S.M.R.; ABDALLA, J.G.F.; JESUS, P.B.R.; ALVES, M.J.M.; TEIXEIRA, N.; JESUS, R.R.; VILELA, M.M.P.; MATTOS, L.R. Avaliação da qualidade de vida de catadores de materiais recicláveis. Rev. Eletr. Enf. v. 14, n. 2, p. 277-85. 2012. https://doi.org/10.5216/ree.v14i2.15259

KUNWAR, R.; ACHARYA, L.; KARKI, S. Trends in prevalence of soiltransmitted helminth and major intestinal protozoan infections among school-aged children in Nepal. Trop Med Int Health. v, 21, n, 6, p. 703-719. 2016. https://doi.org/10.1111/tmi.12700

LAZZARI, M.; REIS, C.B. Os coletores de lixo no município de Dourados (MS) e sua percepção sobre os riscos biológicos em processo de trabalho. Cien Saude Colet. v, 16, n 8, p. 3437-3442. 2011. https://doi.org/10.1590/S1413-81232011000900011

LEITE, M.P.; WIRTH, I.G.; CHERFEM, C.O. Trabalho e resistência na Reciclagem: Movimento Social, Política Pública e Gênero. In: LEITE, M.P; ARAÚJO, A.M.C; LIMA, J.C. (Orgs.). O trabalho na economia solidária: entre a precariedade e a emancipação. São Paulo: Annablume, 2015.

MONIZ, A.P.B. Saúde ocupacional no século XXI: qual o papel do médico de família?. Rev Port Med Geral Fam. v, 32, p. 372-374. 2016. https://doi.org/10.32385/rpmgf.v32i6.11957

NEVES, L.M.; QUADROS, S.O.; LUTINSKI, J.A.; BUSATO, M.A.; FERRAZ, L. Catadores de materiais recicláveis: perfil social e riscos à saúde associados ao trabalho. Hygeia. v. 13, n. 24, p. 162 - 174. 2017.

PEREIRA, V.R.D.; HERNANDES, J.C.; CORRÊA, E.K.; CORRÊA, L.B. Aspectos socioambientais e parasitológicos de catadores(as) de uma cooperativa de triagem de resíduos sólidos. Hygeia. v.12, n. 22, p.123 - 133. 2016.

ROLIM, R. S.; TEIXEIRA, K. M. D.; FERNANDES, R de A. U. "Uns valorizam, outros discriminam": família e sociedade na percepção dos catadores de materiais recicláveis. Oikos: Revista Brasileira de Economia Doméstica, v. 26, n. 1, p. 205-224. 2015. https://doi.org/10.1590/180703102015v27n1p098

SANTOS, T.F.R. Reflexões sobre as Políticas Públicas voltadas aos (às) Catadores (as) de Materiais Recicláveis no Estado da Paraíba: entre as diretrizes nacionais e a implementação local. Revista

$\begin{array}{lllllll}\text { Hygeia } & \text { Uberlândia - MG } & \text { v. } 18 & 2022 & \text { p. 29-43 } & \text { Página } 42\end{array}$


Soroprevalência de infecções e riscos ocupacionais relacionados aos catadores de resíduos sólidos do extremo norte do Brasil
Raphael Barros Rocha João Victor Satrapa Silva Áurea Sérgia da Silva Macêdo Jamilla Karla Corrêa Reis Wagner do Carmo Costa Ana lara Costa Ferreira Leila Braga Ribeiro Fabiana Nakashima Bruna Kempfer Bassoli Bianca Jorge Sequeira

Brasileira de Políticas Públicas e Internacionais. v.3, n.1, p. 206-229. 2018. https://doi.org/10.22478/ufpb.2525-5584.2018v3n1.35429

SILVA, A.P.P. (Re)conhecimento das condições de vida dos catadores autônomos de materiais reutilizáveis e recicláveis do Centro de Fortaleza. Rev. Tecnol. v. 37, n. 1, p. 19-36. 2016. https://doi.org/10.5020/23180730.2016.V37.1/2.19-36

SILVA, C.A.; SILVA, B.; SPOSITO, N.A.; SPEROTTO, R.L. Ocorrência e fatores associados a enteroparasitoses em catadores de lixo. Clin Biomed Res. v, 37, n. 4, p. 295-300. 2017. https://doi.org/10.4322/2357-9730.74403

SILVA, S.P.; $\quad$ GOES, $\quad$ F.L.; $\quad$ ALVAREZ, $\quad$ A.R. Situação social das catadoras e dos catadores de material reciclável e reutilizável: Brasil. Brasília: IPEA, 2013.

SILVEIRA, D.C.; SOUSA, F.F.; TEIXEIRA, C. Relevância Socioambiental da Coleta Seletiva no Município de Itaúna: visão de Catadores e da Comunidade. Fronteiras: Journal of Social, Technological and Environmental Science. v. 8, n. 1, p. 301-318. 2019. https://doi.org/10.21664/2238-8869.2019v8i1.p301-318

SOUZA, G. F. Avaliação ambiental nas cooperativas de materiais recicláveis. Tese (Doutorado em Medicina Preventiva). Faculdade de Medicina, Universidade de São Paulo, São Paulo, 2015.

TEIXEIRA, K.M.D. Trabalho e perspectivas na percepção dos catadores de materiais recicláveis. Psicologia \& Sociedade. v, 27, n. 1, p. 98-105. 2015. https://doi.org/10.1590/1807$\underline{03102015 \mathrm{v} 27 \mathrm{n} 1 \mathrm{p} 098}$

VASCONCELLOS, L.C.F. Vigilância em Saúde do Trabalhador: decálogo para uma tomada de posição. Rev Bras Saude Ocup. v. 43, p. 01-09. 2018. 